\title{
18 \\ THE POSSIBILITY OF COLLECTIVE MORAL OBLIGATIONS
}

\author{
Anne Schwenkenbecher
}

The philosophical literature on collective agency, collective responsibility, social epistemology, and social ontology is burgeoning. Scholarly interest in 'collective' phenomena and theories reflects a persistent desire to tackle an old conundrum - the relationship between individual agents and the collectives they compose. The problem of reconciling these two perspectives is not one for philosophy alone. ${ }^{1}$ There is a notable shift away from a strict individualism towards theories that reflect the fundamentally social, cooperative nature of human activities.

Philosophical enquiry and theorizing has in many ways traditionally been too focused on the individual: the ideal of the autonomous, well-informed, moral agent has dominated ethics, philosophy of action and epistemology for a long time (and arguably still does). In contrast, in political philosophy the question of an inwardly and outwardly just society is often raised without spending enough time exploring what kind of 'collective' a society is and how to understand the relationship between this collective and the individuals composing it.

This chapter attempts to shed light on the issue of collective moral obligations, that is, obligations that individuals in loose groups (as opposed to group agents) may have together. ${ }^{2}$ I take moral obligations to be a basic feature of our moral repertoire. Put in the simplest possible terms, there are things we ought and things we ought not to do. ${ }^{3}$ For instance, we ought not to harm others without good reason and we ought to assist those in need. Further, we might want to distinguish between pro tanto and all-out obligations. Pro tanto obligations are demands on us that give us some reason to act, but which can be overridden by other, more important reasons. All-out obligations are those we ought to meet all-things-considered, taking all the different moral considerations into account.

My contention in this chapter is that our moral obligations (pro tanto and all-out) can sometimes be collective in nature. By this I mean that moral obligations can jointly attach to two or more agents in that neither agent has that obligation on their own, but they - in some sense share it or have it in common. ${ }^{4}$ I will explain this in more detail below.

I believe that the notion of collective moral obligations fills a conceptual gap in philosophy. In a sense, one could say that moral philosophy has traditionally been concerned with the question "what ought I to do?,"5 while what we ought to do as communities has been the focus of political philosophy. But some of the things that we together can (and potentially ought to) do may be neither the political communities' responsibility nor straightforward individual obligations. Furthermore, even where some desirable goal or action is primarily the political 
community's responsibility, as a matter of fact, political agents (e.g. states and their institutions) often fall short of meeting their obligations. In either case, there may be groups of individual agents that can step up and produce the desired outcomes or perform the required actions. Examples include our joint ability to overcome collective action problems even in the absence of state action, such as closing (or reducing) the so-called global emissions gap (Blok, Hohne, van der Leun, \& Harrison, 2012; Wynes \& Nicholas, 2017). On a national scale, our ability to produce herd immunity against some infectious disease should be seen as collective. I will come back to these examples at the end of the chapter. My starting point will be a simpler, small-scale, real-world example of spontaneous collaboration between complete strangers:

Ten passersby witness a car accident in which a motorcyclist gets trapped underneath a car, which has caught fire on one side. Somebody has to act very quickly to pull him out the other side and in order to do so the car will need to be ever so slightly lifted. None of the passersby can lift the car on their own and pull the man out, but together they can (without taking any undue risks to their own health and safety). As it happened, the people manage to lift the car and save the motorcyclist's life. ${ }^{6}$

For the sake of argument, let us assume that the following is the case: it is obvious to the witnesses of the accident that the man is in imminent danger and it is fairly clear what needs to be done to get him out of danger.

There are several scholars who argue that under circumstances such as these individual moral agents can be under a collective obligation (or have collective responsibility) to assist (Held, 1970; Isaacs, 2011; May, 1992; Miller, 2010; Pinkert, 2014; Schwenkenbecher, 2013, 2014, 2019; Wringe, 2005, 2010, 2016). Collective obligations, on their accounts, are distinct from and not reducible to individual obligations (to contribute to cooperative ventures, for instance).

In the following, I will distinguish different ways of spelling out such collective obligations. But before I do so, let me briefly talk about why anyone might think that we need the notion of collective obligations. One of the starting points of many debates on collective obligations is the observation that in cases like the one above in order to produce the morally best outcome, or in order to perform the action most likely to secure that outcome, individual agents need to cooperate with one another and coordinate their individual actions. It takes more than one person's effort to make a difference to the person in need.

More generally, there is a class of actions (and outcomes) that cannot be performed (or produced) by one person on their own. They require at least two people in order to be realized and no one individual agent can guarantee the success of the collective endeavor. These cases are characterized by 'joint necessity." Playing a duet is a joint necessity type of activity. By definition, it cannot be done by one person. Another example is 'talking past one another.' Joint necessity can be analytic (as in the two examples just given), where it is part of what it means to do $x$ that $x$ is done by at least two people. Or joint necessity can be circumstantial, where as a matter of fact (rather than as a matter of principle), something cannot be done by one person, for instance, if it takes two or more people to lift a heavy table (or a car, for that matter).

We can further distinguish between strict and wide joint necessity. ${ }^{8}$ For strict joint necessity to apply, the number of available contributors to a collective outcome equals the number of contributors minimally necessary to produce it. What it means to be an available contributor would depend on the outcome in question. For the motorbike accident described above, it would mean anyone close enough to see what is happening and able to make some kind of contribution. For strict joint necessity, the success of the joint venture is counterfactually dependent 
on each available contributor playing their part. It is entirely within my power to stymie any efforts of our duet playing and the same applies to you.

Wide joint necessity applies where there are more available contributors to a joint outcome than minimally necessary. There are many large-scale examples of wide joint necessity such as producing herd immunity (against a certain infectious disease), bridging the emissions gap (UNEP, 2017), or producing a referendum outcome in favor of marriage equality. In order for herd immunity against a particular communicable disease to be achieved it is not necessary that everyone who can safely be vaccinated be in fact vaccinated. Depending on the disease, the figure may be around 90 percent. What this means is that, in contrast to strict joint necessity cases, my unilateral defection in a wide joint necessity case does not guarantee collective failure and neither does yours. This might lead someone to the conclusion that therefore individual obligations to contribute to such goods are always less stringent. But I think this would be the wrong conclusion to draw, as I shall show below.

In many joint necessity scenarios, something morally important is at stake. Especially where lives are in imminent danger, people tend to share the intuition that those who could help ought to do so, e.g. those witnessing the motorbike accident ought to assist the trapped person. But this common intuition may create a dilemma, because, no individual can guarantee the success of the joint endeavor (or produce the desired collective good). ${ }^{9}$ That is, individually, none of these passers-by can assist the trapped motorcyclist. Hence, it cannot be any individual agent's obligation to rescue him. They can only help jointly. So, whose obligation is it? We might want to say that it is the obligation of all of them together. But what does that mean? Is it the 'group' of passers-by that has the obligation to assist? Or is there 'merely' an obligation on each of us to do our best given others' actions? The answer is not straightforward. In my view, this impasse is regularly felt when we try to make moral decisions: it is the pull between the individualist option (to do something that is under one's individual control only) and the collectivist option (where the success of one's actions often depends on others' contributions).

Scholars have chosen different routes to answer the question about the locus of moral obligation in joint necessity cases. Roughly, they can be divided into two groups, which I will call 'conservatives' and 'revisionists.' Revisionist scholars will usually introduce new moral vocabulary and concepts to fill what they believe to be a gap in traditional moral theorizing where joint necessity is concerned. Many argue that there is some kind of group-level obligation (or responsibility) that applies to loose collections of individuals such as the passersby in scenarios like our exemplary case (Held, 1970; Isaacs, 2011; May, 1992;Wringe, 2010). Other revisionists, including myself, speak of individuals holding joint obligations (Miller, 2010; Pinkert, 2014; Schwenkenbecher, 2013, 2014, 2019) or sharing obligations (Björnsson, 2014). Conservative scholars, in contrast, do not see the need for new conceptual tools, but attempt to resolve collective action puzzles in a way that is maximally continuous with existing theory. They tend to argue that joint necessity cases give rise to (perhaps slightly more complex than usual) contributory duties only. According to Parfit, for instance, each of the individual passersby simply has an obligation to contribute if she thinks that enough others contribute to get the joint endeavor off the ground (Parfit, 1984). Collins and Lawford Smith would argue that each ought to take steps towards forming a group that can then act as an agent (Collins, 2013; Lawford-Smith, 2015).

I will not discuss the merits of these different types of approaches in any detail here, since I have done so elsewhere (Schwenkenbecher, 2018). The obvious downside of the conservative approach is that the obligation to produce the collective good (or to realize the joint endeavor) is not allocated. In our example, then, there is no obligation to free the trapped motorcyclist, 


\section{Possibility of Collective Moral Obligations}

even though individual agents have obligations to contribute. ${ }^{10}$ Holly Lawford-Smith acknowledges this problem for the conservative approach, but bites the bullet because she thinks the advantages of this approach still outweigh its disadvantages (2015). In contrast, the obvious downside of the first type of revisionist approach is this: it seems to be built on the assumption that there is a (novel) entity, a group agent of sorts, that can not only act on the problem at hand, but has a sufficient level of unity such that it can hold a moral obligation (or be held morally responsible). Revisionist scholars have tried to avoid this kind of criticism by arguing that being an agent is not a necessary condition for being the bearer of a moral obligation as far as groups (or collections of agents) are concerned (Wringe, 2010).

However, my aim here is not to give an overview of the literature but to instead flesh out my own (revisionist) approach to collective obligations and show how it applies in a range of cases. ${ }^{11}$ This approach, while revisionist, avoids the objection sketched above by refraining from postulating a group agent (even a putative or potential one) and instead conceiving of the obligations to assist in joint necessity cases as shared or 'joint.'

\subsection{Jointly Held Obligations}

What does it mean to say that a number of agents jointly hold a moral obligation? On my view, collective obligations are not a novel type of obligation, but are moral obligations held in a collective mode: I can individually hold an obligation to do $x$ or we (for instance you and I) can jointly hold an obligation to do $x$ (for instance where $x$ is only collectively feasible). To jointly hold an obligation is a plural predicate - it can only meaningfully apply to two or more agents, very much like other (non-moral) plural predicates such as 'playing a duet' or 'walking past one another.' On this approach, the obligation that the passers-by in our example assist the trapped driver is a joint obligation; they hold it together.

Joint obligations give rise to further individual obligations. If you and I jointly have an obligation to lift a heavy table, then each of us has an individual obligation to do our part or make an effort towards the joint endeavor. But joint obligations do not reduce to individual obligations to play our part. In order to see why, let us return to wide joint necessity cases, where we have more potential contributors then minimally necessary for the success of the collective performance. Suppose that it takes two people to lift a heavy table, but three potential contributors are available. Suppose further, that two is also the maximum number of people who can successfully lift the table together, because of the way each needs to position themselves to lift it. So out of the three potential contributors only two should act. It cannot be the case that each of the three has an obligation to act (since a three-way effort will not succeed). Neither should we think that any combination of two people (out of the three) is obligated to contribute. Because if we did, we would either (i) arrive at an impasse where we could not say exactly which two people have these obligations (that is, we would arrive at the following disjunctive obligation: Either $a$ and $b$ are obligated to do their part in lifting the table together, or $b$ and $c$ are so obligated, or $a$ and $c$ ). Or, (ii) we would have to make an arbitrary decision on which two people have these obligations.

Instead, I suggest that the joint obligation is on all three and the individual (contributory) obligations will be derived from it. For instance, we may all be under an obligation to see to it that two of us lift the table together and one of us makes sure not to interfere. In order to do this, we will usually have to communicate with each other. This may be non-verbal communication. In everyday life, we often coordinate our actions this way - just think of a scenario where some passersby rush to help someone who has trouble lifting a pram into a bus while others stay behind ready to step up if necessary. 
But we need not always be able to communicate with each other in order to acquire (and discharge) a collective obligation. Sometimes having the right information concerning the other agents' beliefs will suffice. Suppose that you and I live on opposite shores of a protected lake and in order to preserve the lake's sensitive ecosystem and keep its pristine water clean we are instructed (by the local council) to ensure that no sewage or gray water enters the lake. We also learn that every neighbor is being thus instructed. Now I can do my part of not allowing any polluted water to enter the lake and so can you. But neither of us can guarantee that the lake's water is not compromised. That outcome we can only produce together. Assuming that the pristine ecosystem is valuable and no overriding concerns exist, we are under an obligation to protect it. This obligation is held by both of us, jointly. It is not an obligation held by either of us, because neither can discharge it alone. Note that this does not require us to act together in the strict sense. Note also, that a joint plan is in place (via the local council's communication), which ascribes to each of us a clearly circumscribed role in the collective effort (and which, furthermore, communicates that very fact to each of us).

\subsection{Collectively Available Options and We-Reasoning}

So when exactly should we think of our obligations as collective? I shall explain the conditions in the following. To start with, I argue that two (or more) agents have a collective moral obligation to do $x$ if $x$ is an option for action that is only collectively available and if each of them has sufficient reason to rank $x$ the highest out of the options available to them.

Let me explain what this means. In a scenario like that of the trapped motorcyclist each individual could reason in the following way: "I can walk over and attempt to lift the car but on my own I will not be able to lift it. Trying to lift it will only make sense if several other bystanders also contribute."

Naturally, most of us would probably make an attempt to get others to contribute (provided no countervailing circumstances obtain). But why is this so? To me it seems that the reason why one would try to establish collective action in this kind of scenario is because it seems like the (morally) best option.

Before I continue note two things here: I do not commit to a view on what actually is morally best in this scenario, that is, I make my argument independently of any particular substantive moral theory. Evidently, different substantive theories vary significantly in what they consider morally best. However, I am hoping that the example used here is one where the major moral theories and common moral intuitions converge. Further, note that calling an option 'morally best' does not imply that I am committed to some kind of consequentialism. The morally best option for a Kantian may be to respect someone's autonomy and for a Virtue Ethicist it may be to act in the way most constitutive of eudaimonia.

Returning to our individual decision-maker: Let us assume that she perceives the option as best where several passers-by lift the car together. It is important to note that this option is not actually available to her (alone), but it is only available to them. At the point of making her move to assist the trapped driver, our deliberator does not yet know exactly how many people will be needed and how many of the other passers-by are willing and able to contribute and who they are. Still, she acts on what she perceives to be the optimal option for acting in this case (jointly lifting the car) and she infers her own (and potentially others') individual contributory action(s) from that collectively available option. ${ }^{12}$

If that is what our individual deliberator does, then she we-reasons. This means that the starting point of her deliberation is not merely the options available to her (individually). Instead, she also includes in her deliberation those options that are only collectively available, 
such as lifting the car and freeing the trapped motorcyclist. She reasons from the top-down, so to speak. Starting from the best option (which is only collectively available) she derives individual contributory actions.

I am not alleging that someone who acts like our exemplary deliberator necessarily engages in we-reasoning, but empirical evidence suggests that people faced with similar scenarios regularly do (D. Butler, 2012; D. J. Butler, Burbank, \& Chisholm, 2011). And my contention here is that they often should.

Let me now explain the idea of 'we-reasoning' in some more detail. The way I am using the term is slightly different from how similar ideas of reasoning from the collective perspective are employed e.g. in philosophy of economics and (non-standard) game theory (Bacharach, 2006; D. Butler, 2012; Gold \& Sugden, 2007; Hakli, Miller, \& Tuomela, 2010; Sugden, 2015; Sugden \& Gold, 2007; Tuomela, 2013). ${ }^{13}$

Importantly, I am adopting the term from its original context of decision-theoretic discussions of strategic interaction for the field of moral deliberation and decision-making. As moral agents, we regularly face problems wherein the outcome of our actions depends on how others choose. There are two ways of deliberating about our own choices in such cases. We can either think of our choices as best responses to others' choices (I-mode reasoning). Or we can think of our own choices as contributions to the collectively best option (even when we do not know how others are (likely) to choose) (we-mode reasoning).

Let me illustrate this by returning to the example of the trapped motorcyclist. The individual passerby might reason in the following way:

If sufficiently many others contribute then the morally optimal thing for me to do is to also contribute (provided that this will make a difference to the outcome). If not enough others contribute then the morally optimal thing for me to do is not to try to lift the car on my own, but perhaps to call an ambulance or the police.

This would be an instance of I-mode reasoning (I am adopting this term from Hakli et al. 2010).

Or, the individual passer-by might reason differently:

The morally best outcome is the one where several people join forces to lift the car and free the trapped driver. In order to secure the morally best outcome, each of us should make an effort towards lifting the car. I should get others to make an effort in lifting the car and signal to others my readiness to contribute to the joint endeavor.

Note that this involves two steps: (i) we-framing means to include collectively available options in one's option set when deliberating about which option is best and identifying an option that is only collectively available as optimal. In a second step, (ii) the deliberating agent determines her individual course of action as playing her part in the collectively optimal course of action. If this is how the individual passerby reasons about what she should do, then she is employing we-reasoning. ${ }^{14}$

There are many joint necessity scenarios where by default most of us would reason in this way. Not only would we include collectively available options in our deliberation (weframing), but also we would take individual steps towards realizing those options as well as encourage others to take the necessary steps. This may (but need not) include communicating our intentions and goals to others, asking them to contribute, or distributing and coordinating tasks and roles. Often we will play our part without having information on what others are 
doing; we will take a gamble, so to speak (for instance when we are not diverting gray water into the pristine lake).

Sometimes, individual roles or contributory tasks will be clear from the very start. This may be because there exists a joint plan or a habitual pattern of actions for a particular joint endeavor. Take the example of jointly setting a table, for instance. Or a traditional dance or a tune that people know well enough to perform it together instantly.

At other times, it may be relatively straightforward for individual agents to jointly work out a plan and individual contributions if they can communicate with each other. The other day I asked a friend to help me lift my canoe onto the roof rack of my car. We had to adjust our individual contributory actions on the go, but it was fairly easy to do so. If we did this more often, we might form a habitual pattern and could possibly even do this without important communicative (for instance visual) cues.

There are other cases where such patterns, while not habitual or engrained, can be easily established by potential contributors without any need for communication between them. It may be obvious what the collectively best choice is and how each person can contribute to realizing it (as, for instance, in a Hi-Lo game kind of scenario ${ }^{15}$ ). One example would be voting in a referendum on a morally black and white matter, such as the right to have an abortion (as happened in Ireland recently) or the right of same-sex couples to marry (as happened in Australia recently).

But there are also cases where communication is difficult or even impossible and where individual agents cannot divine their contributions to the joint task without communicating to the other agents. Arguably, in those cases individual agents would be less inclined to wereason. That is, they may be (and probably should be) less inclined to include options that are only collectively available in their moral deliberation and to take steps towards realizing those options.

\subsection{Joint Ability and Ignorance}

Further, we might say that in such cases the joint ability of potential contributors to perform an action or produce an outcome together is severely diminished. That is, there will be circumstances under which the success of joint action is so unlikely that a collection of agents cannot be said to have the level of joint capacity minimally required for ascribing an obligation to them.

Two agents, $a$ and $b$, have joint ability ${ }^{16}$ to do $x$ if there is at least one combination of contributory actions such that

- these are genuine options $a$ and $b$ have, and, if both are performed in the right way, they produce $x$

- both contributory actions are compossible;

- $\quad a$ and $b$ are capable of performing these actions with a view to combining them.

Let me explain the last condition: Joint ability is not mere compossibility. Rather, agents must in principle - be able to willingly combine their actions. That is, they must be in a position to intentionally perform their contributory action as a contributory action. ${ }^{17},{ }^{18}$ There must be some reason for agents to form plural intentions in the most minimal sense as intentions the content of which is some collective endeavor (Ludwig, 2016). ${ }^{19}$ This is important, because otherwise we could ascribe joint ability wherever an outcome could accidentally be jointly produced. But surely, the accidental production of any outcome by some agent (or group thereof) should not 
be mistaken for a robust ability to produce that outcome where this robust ability is the basis for ascribing moral obligations.

Joint ability, then, is highly context-dependent and particularly sensitive to shared (or even common) beliefs. ${ }^{20}$ As such, joint ability can be deliberately generated in a given collection of agents by providing information related to collective goals and contributory actions. ${ }^{21}$ In fact, public information campaigns concerning specific collective causes do precisely that: they communicate collectively desirable patterns of action and outline those individual contributory actions, which are most likely to produce the collective pattern. This does not only solve (or prevent) coordination problems, but it also generates joint ability in the sense that people may now reasonably form intentions concerning their contributory actions as contributory actions where perhaps such intentions would not normally have been formed. Where small-scale joint necessity problems are concerned, we commonly (and without thinking much about it) inform others of the problem at hand, the potential patterns of action that will resolve it and encourage others to make their contribution ("Do you mind giving me a hand with this? If you just [do $x]$ then I will [do $y] \ldots$...).

In other words, knowing of possible joint initiatives to address collective action problems will reduce or remove propositional ignorance of the issue concerned. A person is propositionally ignorant of a proposition $p$ if they do not know of $p$ (Le Morvan, 2011). For instance, someone may have never heard of anti-microbial resistance and therefore will not form intentions to contribute to the reduction of such resistance by changing her dietary habits, for instance (Giubilini, Birkl, Douglas, Savulescu, \& Maslen, 2017). Further, information campaigns may reduce or eliminate factive ignorance, that is, they may correct false beliefs on the matter at hand. For instance, people may believe that there is nothing we can do to stop run-away climate change, but we may learn that there are things we can each do that will have a significant impact on mitigating global warming (Blok et al., 2012; Dietz, Gardner, Gilligan, Stern, \&Vandenbergh, 2009; Wynes \& Nicholas, 2017). Factive ignorance, then, can also prevent agents from having reasons to form minimal plural intentions to perform their contributory action as a contributory action.

It is easy to see that in our main example, the case of the trapped motorcyclist, we will hardly need to worry about propositional ignorance. To each of the passersby it is immediately obvious that the person is in need of help and that he must be pulled out from underneath the burning car. Where the respective (collective action) problem is less immediate (as is the case for problems concerning 'distant strangers, for instance), propositional ignorance will become a major factor in collective apathy and inaction.

In our exemplary case, there may be some factive ignorance as to whether the random group of strangers is in fact capable of lifting the car and extracting the driver, but in the real-world case, the passers-by were confident enough to try. The more immediate a problem, the less likely it is that agents are propositionally ignorant concerning that issue. Factive ignorance, in contrast, can have all kinds of causes, including emotional and psychological factors, and as such is often difficult to combat.

If we think that forming intentions to act depends on having certain beliefs (as I have been alleging) then interesting questions arise where we think that an agent or a group of agents can be held responsible for their suboptimal epistemic position. Take the example where a group of agents is factively ignorant of some harm they are collectively causing and they therefore continue to perform the actions that in aggregation cause harm. For instance, this was the case before the climate greenhouse effect was widely known. On my account, people who lived during the industrial revolution were not in fact jointly able to prevent global warming because their epistemic position was not such that they could have formed the intention to reduce (or 
abstain from) their fossil-fuel burning activities as part of an effort to prevent global warming. ${ }^{22}$ This is not because there were no (feasible or economical) alternatives to burning fossil fuels and neither is it because they were not (accidentally or incidentally) capable of preventing the release of massive amounts of greenhouse gases in the atmosphere, but rather because they could not have formed the relevant intentions to contribute to a joint effort to prevent aggregate harm, because they were ignorant of that harm. In other words, their ignorance undermined their joint ability. But were they responsible for that ignorance? And if so, can we say that they were culpable for their lack of joint ability?

I cannot discuss here which criteria should make us consider an agent blameworthy of her ignorance, but will simply point to some of the literature on this topic (Le Morvan, 2011; Peels, 2010, 2016; Rosen, 2003; Zimmerman, 2016). What we may be able to say, though, is that where a proposition is public knowledge, agents will be less justified in claiming ignorance. A proposition is public knowledge if (a) most people believe that the proposition is true and (b) most people believe that (a) is the case.

\subsection{When Do We Have Collective Obligations?}

To sum up what has been said so far: In order for two or more agents to jointly hold an obligation to address some joint necessity problem they must have joint ability to address that problem. We also discussed that in deliberating about the right (individual) course of action visà-vis collective action problems, agents regularly we-frame the case at hand, that is, they include options in their deliberation that are only collectively available, and they we-reason with regard to their individual contributory actions.

It is a necessary condition for collective obligations that potential collaborators facing a joint necessity case have grounds to privilege we-reasoning over reasoning in I-mode. But under which circumstances do agents have such grounds? It is easier to give negative conditions for when agents lack such grounds. For instance, they will have no grounds for engaging in wereasoning if they do not recognize the problem as a joint necessity case. Further, they may not recognize a joint necessity case as a morally pressing problem in need of resolution. Or else they may not be aware of other agents' potential to contribute. Finally, they may have reason to believe that they are on their own with regard to the problem, because agents appear unwilling to contribute. However, if the problem is pressing enough, the conscientious agent must not give up at this point, but ought to attempt to secure the others' cooperation.

The picture of joint obligations drawn here aligns best with a non-objective view of moral obligations. On an objective view of moral obligations, we ought to do what is objectively best (or right) regardless of whether we know what that is. So even if we act conscientiously, on the basis of the best available information, and are rigorous in our decision-making, we may still fail to meet our actual moral obligations. Likewise, we may meet them accidentally. I do not have the space here to argue against the objective view of moral obligations and will instead refer the reader to Michael Zimmerman's work on this issue $(1996,2014)$.

The notion of collective obligations defended here, aligns best with what Zimmerman (1996) calls the prospective view of moral obligations. ${ }^{23}$ To put it in a nutshell: on the prospective view, we ought to do what is prospectively best, that is, what our best bet is given the obtainable evidence and provided we have conscientiously availed ourselves of the evidence. This means that our moral obligations depend on our reasonable, justified (but not necessarily true) beliefs concerning the problem at hand.

The prospective view of moral obligations makes better sense of the intuition that agents have no collective obligation to address a joint necessity problem where they reasonably believe 
an individually available option to be superior to an only-collectively-available option. Or where they reasonably disagree on which collectively available option is best and they therefore cannot agree on a course of action. Or where they are unlikely to figure out the collectively optimal solution in the time available to them. These kinds of complications, where they cannot easily be resolved between willing agents, can cancel collective obligations.

To illustrate the prospective view of collective obligations, let us once more return to the case of the trapped motorcyclist: The passers-by are likely to include the option of (collectively) lifting the car and extracting the driver in their set of options for moral deliberation unless they have reason to believe, e.g., that there is no one available to help them. Of course, because the stakes are so high they may still try on their own to pull out the driver, essentially testing if the option of rescuing him is individually available. However, this action is simply a way of availing themselves of evidence in a conscientious manner. Passersby will usually attempt to investigate others' willingness to contribute - this serves to determine which options are available to them ${ }^{24}$ and, potentially, it can be the moment where individual roles or contributions are distributed. Further, it generates common knowledge amongst potential contributors, and therewith increases (or even establishes) joint ability. The same action can also deliver important information for each individual deliberator with regard to how others rank the available options and the extent to which they are willing to make their contribution. What they have an obligation to do will depend on what they have good reason to believe is the best option, given they have availed themselves of the evidence. That evidence will often include information about other agents' willingness and ability to contribute.

Such information will often be crucial for whether or not the pro tanto joint obligation becomes an all-out obligation. To reiterate, an all-out obligation is an obligation all-thingsconsidered. Whether or not anyone (or any group) has an obligation all-things-considered depends on how highly a particular option for action ranks for the respective individual(s) amongst competing options. Or, in other words, it depends on whether the reasons that speak in favor of that option outweigh the reasons speaking in favor of any of the alternative options. Awareness of others' likelihood to contribute will strengthen those reasons in favor of the collectively available option, other things being equal. ${ }^{25}$

On my view of collective moral obligations, two or more moral agents jointly hold an allout obligation to perform an action or produce an outcome corresponding to a collectively available option if each of these agents, provided that she is conscientious, ...

i. ... has reason to believe that the collectively available option (joint rescue) is morally best;

ii. ... has reason to include that option in her deliberation about her obligations (we-framing the problem);

iii. ... has reason to deduce her individual course of action based on (i) and (ii) (we-reasoning about the problem) and the ability to do so;

And if the agent ...

iv. ... has no overriding obligations, is not unduly burdened by the task, and is jointly capable with the other(s) of discharging the task at hand. ${ }^{26},{ }^{27}$

The first three conditions may be met either consecutively or simultaneously. Further, weframing (ii) and determining individual courses of action (iii) will usually (but not necessarily) mean that agents communicate amongst each other, even though this need not be verbal communication. If one of the passers-by in our example observes another placing their hands on the car in an attempt to lift it then they usually have a reason as per (ii) and (iii). 
It is obvious now that our main examples came with a few implicit assumptions, which are responsible for the initial plausibility of the claim that the agents involved have some all-out duty to assist. This was necessary to get the argument off the ground. For instance, the scenarios were characterized by a certain moral simplicity. The features of the situations described were such that rescuing the person (or protecting the lake) would presumably be the morally best response. That is, most major moral theories would converge in their action recommendation. Further, in taking these scenarios out of context and discussing them at a certain level of abstraction we simply ignored other factors that would play a role for moral deliberation. For instance, we did not discuss any competing obligations that our passers-by (or the lakeside neighbors) may have, but simply assumed that there were none that would override the obligation to assist. Further, in the cases presented the objectively best option corresponded to the option that was perceived to be best by potential contributors (that is, the objective and the prospective view on obligations would align in these cases as to their action recommendation). Further, the joint rescue case is a one-off problem that requires no recurring sacrifice. Apart from moral simplicity, we also assumed epistemic simplicity: the problems were fairly obvious to an ordinary agent and so were the solutions. The number of potential contributors was manageable and they could communicate directly with one another. Naturally, more often than not these favorable conditions will not obtain. What impact do moral and epistemic uncertainty have on our collective obligations? The short answer is: the same impact as they have on our individual obligations. We frequently make decisions about what we ought to do under conditions of uncertainty and risk. As such, assumptions concerning which of our many pro tanto obligations become all-out obligations will always be somewhat approximate.

However, it may seem that more needs to be known or possibly investigated by individual agents if they are to jointly hold an obligation, compared to individually held obligations. This is true insofar as some knowledge concerning the others' willingness and ability to contribute to a joint endeavor are concerned. On the other hand, joint agency often calls for the sharing of (epistemic and other) expertise and burdens. Often, we do not each need to know how exactly to address some problem in order to jointly address it, as long as between us we have enough expertise to do so. In this regard, the threshold to acquiring collective obligations may in fact be lower than it is for individual obligations, or, put differently, the former may at times be more easily defeated than the latter.

\subsection{Large-scale and Global Moral Obligations}

Let me conclude by commenting on a controversial question, that has been receiving some attention in the literature: the problem of large-scale and even global collective obligations (Isaacs, 2011; Lawford-Smith, 2015; Schlothfeldt, 2009; Schwenkenbecher, 2013, 2017; Wringe, $2005,2010)$. In the examples used above, I suggested that we may have collective obligations to mitigate climate change through aggregate emission reductions. But is this really so? Can we - meaning 'humanity,' or the 'global rich,' or 'citizens of industrialized nations' - really have collective obligations to resolve such problems? That is, can individuals forming part of large, dispersed, non-organized groups, have collective obligations to jointly bring about some outcome or perform some action? ${ }^{28}$

One of the challenges of making definitive claims about 'global moral obligations' is that the problems these obligations are supposedly meant to address are usually extremely complex, unlike the fairly simple cases discussed above. This increase in epistemic complexity brings with it a certain ambiguity and vagueness in the ascription of obligations and responsibilities, not just in the collective case, but for individual duties, too. 
Having said that, we might say that some large-scale collective action problems really are not too complex to be addressed by large and dispersed groups with no significant level of organization if they are in a position to produce desirable outcomes by way of aggregating individual actions or their effects.

Here is one example: Herd immunity against some disease - that is, the absence of the pathogen causing it - is a public good that is only produced if in a given population the vaccination rate is above a certain minimum threshold. Where herd immunity is undermined by lower-than-necessary vaccination rates, those who cannot be vaccinated because they are too young, too old, or ill, are at risk of contracting the respective disease, which - in the worst case may lead to death. Protecting these vulnerable groups from the respective disease is only collectively possible: a sufficiently high percentage of people in that population must be vaccinated. Here it seems easy to stipulate a collective obligation, at least for those groups to whom these causal links are known. Again, public information campaigns can further increase public knowledge of the interrelation of vaccination behavior and deaths from these often-archaic diseases. The collectively optimal pattern of action and individual contributory actions are obvious and they are generally not too costly.

Let me now return to the problem of climate change mitigation. Do we have collective obligations to address this problem through the combined effect of individual action choices? Clearly, climate change mitigation is much more complex a goal than herd immunity, for instance. Let me therefore make a conditional claim: If climate scientists are correct in assuming that aggregate individual behavioral changes can have a significant if not decisive impact on closing the global emissions gap ${ }^{29}$ (Blok et al., 2012; Wynes \& Nicholas, 2017) then I see no reason why we (capable citizens around the world ${ }^{30}$ ) should not in principle have an obligation to make those behavioral changes with a view to contributing to large-scale collective action on climate change. However, I believe that public knowledge concerning the gap and the measures to reduce it is currently insufficient for grounding an all-out collective obligation to reduce or eliminate the emissions gap.

The crucial role that direct interaction and communication play in coordinating spontaneous collective endeavors (such as the joint rescue of an injured motorist) and establishing the epistemic conditions for we-framing (and agency transformation) can potentially be fulfilled by other means, such as public information campaigns, blogs, social media, etc. when it comes to large-scale collective action. However, the latter will usually require greater levels of organization and leadership and where these are absent we may lack the prerequisites for holding collective moral obligations to address these issues.

\section{Acknowledgments}

The author gratefully acknowledges financial support from the School of Arts at Murdoch University (2017) and an Oxford Martin Visiting Fellowship by the Oxford Martin School (2017-2018) to conduct research for this chapter. Further thanks go to the editors, Deborah Tollefsen and Saba Bazargan-Forward, for their constructive feedback on earlier drafts of the chapter.

\section{Notes}

1 To give just three examples from outside philosophy: Behavioural economists like Michael Bacharach emphasize the importance of 'team reasoning' in strategic interaction, and evolutionary biologist Michael Tomasello posits the adaptive advantage from 'collective intentionality' in our ancestors' 
thinking ((2006) (2014)) Olson, M. (1971). The Logic of Collective Action: Public Goods and the Theory of Groups. Cambridge, MA: Harvard University Press.

2 I am referring to group agents as described by List and Pettit (2011) or Tollefsen (2015).

3 I cannot say much more about this without abandoning the required level of generality. How moral obligations as such are grounded is a question that cannot be addressed here. In particular, I will refrain from committing to any 'substantive' moral theory.

4 To jointly have an obligation is a plural moral predicate, much like to play a duet is a plural non-moral predicate.

5 Exceptions include Donald Regan's and Derek Parfit's works (Parfit, 1984; Regan, 1980).

6 See www.telegraph.co.uk/news/worldnews/northamerica/usa/8761446/Trapped-motorcyclist-savedby-bystanders-who-lifted-burning-car.html. There are countless other examples of strangers collaborating spontaneously to save the life of perfect strangers or to protect them from harm. See for instance www.abc.net.au/news/2014-08-06/man-freed-after-leg-trapped-in-gap-on-perth-train-station/ 5652486 (both accessed July 7, 2018). I have used structurally similar examples in Schwenkenbecher 2013, 2014, and 2019, and so have a number of other scholars, such as Collins 2013 and Wringe 2016.

7 I am adopting this term from Lawford-Smith (2012).

8 I first introduced this distinction in Schwenkenbecher (2017).

9 Another problem may arise if this turns out to be a wide joint necessity case, because it would then seem that in addition to being individually unable to guarantee the success of the collective endeavor, each passerby is also not strictly speaking necessary for its success. I leave this problem aside here and will return to it later.

10 Consequently, in a case of collective omission, no one would be blameworthy for the failure to free him. Further, if individual contributory obligations are understood as conditional, we run into the problem of mutual release. Simultaneous non-action by all potential contributors voids obligations of the kind "I ought to help if the others do" (see Goodin 2011).

11 For a more detailed defence of this account, see Schwenkenbecher (2019).

12 An option for acting is 'collectively available' if it is an option for two or more agents acting (or producing an outcome) together, but not something an individual can do (or bring about). For instance, the option of getting married is not available to me as an individual. It is only available to me and another person together.

13 My notion of 'we-reasoning' is equivalent to what Hakli et al. (2010) called 'we-mode reasoning.' It differs from what Gold and Sugden (2007) and Sugden and Gold (2007) call 'team-reasoning' in that it is not a joint (or team) effort.

14 A more detailed account of the difference between I-mode reasoning and we-mode reasoning can be found in Schwenkenbecher (2019).

15 This is a payoff-matrix for a Hi-Lo game. We can easily imagine moral decision-making scenarios that have this structure. Even when each player is ignorant of the other player's choice, it seems obvious that they should pick option A.

\begin{tabular}{lllll}
\hline & & & \\
& & Player 2 & \\
Player 1 & A & B & Hi $>$ Lo $>0$ \\
& A & Hi/Hi & $0 / 0$ & \\
\hline
\end{tabular}

16 Joint ability is temporal and comes in degrees.

17 This requires at least that agents are able to conceive of a collective pattern of actions, which their own and other agents' individual actions could form part of. It does not require them to believe that others are likely to perform their contributory actions within the pattern, only to think that they could conceive of their individual actions as part of such a pattern. Stemplowska (2016: 286) argues that if we have good reason to believe that other agents are not in a position where they can conceive of their individual contributory actions as forming part of such a collective pattern, then a collective action should be considered unfeasible:

$[A] n$ action of each of three billion people touching his or her nose next Tuesday is correctly classified as unfeasible because there are not three billion people who could know next Tuesday 


\section{Possibility of Collective Moral Obligations}

how to do it or that their individual contributions are needed. (Of course it remains open that this may become possible in future, in which case the action will become feasible then.)

(Stemplowska, 2016)

18 In a wide joint necessity case, the same clause applies. It must be possible for each to intentionally perform their contributory action, which may mean to refrain from contributing where their contribution is either superfluous or detrimental to the success of the joint endeavor.

19 I cannot go into the debate on collective intentions or 'we-intentions' here. Suffice to say that plural intentions in the minimal sense are not interlocking intentions (of the kind that Michael Bratman (2014) focuses on), but 'independent' individual intentions.

20 A belief that $x$ obtains is shared between two agents if each agent believes that $x$ obtains. It is a common belief if it is shared and if each agent knows that it is shared (first order common belief). See also (Roy \& Schwenkenbecher, under review).

21 This is what Scott Shapiro refers to as a 'shared plan' (Shapiro, 2014).

22 One might extend this period of blameless ignorance to the second half of the twentieth century. I am assuming that Svante Arrhenius' discovery of the greenhouse effect towards the end of the nineteenth century was not public knowledge for a long time. However, at the very latest with the adoption of the UNFCCC in Rio de Janeiro in 1992, climate change and the greenhouse effects should have been widely known.

23 It should be noted, though, that Zimmerman is an individualist about moral obligations and would probably not subscribe to the idea of collective obligations defended here.

24 Bacharach (2006) and others (e.g. Butler et al., 2011) insist that we-reasoning involves what they call 'agency transformation.'This means that individuals consider the group the locus of agency, rather than themselves (see also Woodard, 2011).

25 Another way to put this is to say that it depends on which moral reason(s) for action outweigh all others (see e.g. Woodard, 2011).

26 It should be noted that these conditions are jointly sufficient for collective obligations, but are not all necessary. This is because such obligations can also arise in the absence of joint necessity where one person alone can produce a morally optimal outcome or perform the corresponding action, but it is a matter of fairness that another agent (or other agents) help her in doing so. Cases of joint obligations arising from distributive justice rather than joint necessity are not discussed here.

27 Finally, whether or not a pro-tanto collective obligation becomes an all-out collective obligation depends on whether or not for the contributing agents there are competing overriding (collective or individual) duties. Or, to put it differently, it depends on whether or not the group-based reasons for contributing to the collective endeavor weigh heavier than other reasons (on group-based reasons for action see (Woodard, 2017).

28 This question is different from that of ascribing duties to group agents such as states or international organizations. The question of duties of the global citizenry (if you like) or humanity arises not least, because those (group) agents whom we would consider principally responsible are failing in resolving problems such as climate change or global poverty. However, I do not claim that states' and other political agents' failure to resolve these problems is the only or even the major source of joint obligations to address large-scale collective action problems.

29 The emissions gap is the gap between the level of emission reductions required for limiting global warming to maximally $2^{\circ} \mathrm{C}$ (with a high probability) and the emission reductions states have currently committed to (UNEP, 2017).

30 A fully-fledged argument for this conclusion would need to specify who counts as 'capable' in this regard. My first instinct would be to suggest that anyone who has the economic, intellectual, and epistemic capacity to make such behavioral changes without incurring disproportionate costs. Obviously, this need not be tied to certain nationalities - it may well be that a rich person from Zambia is more 'capable' in this sense than a poor person from the United States.

\section{References}

Bacharach, M. (2006). Beyond Individual Choice: Teams and Frames in Game Theory. Princeton: Princeton University Press.

Björnsson, G. (2014). Essentially Shared Obligations. Midwest Studies in Philosophy, 38(1), 103-120. 
Blok, K., Hohne, N., van der Leun, K., \& Harrison, N. (2012). Bridging the Greenhouse-gas Emissions Gap. Nature Climatic Change, 2(7), 471-474.

Butler, D. (2012). A Choice for 'Me' or for 'Us'? Using We-Reasoning to Predict Cooperation and Coordination in Games. Theory and Decision, 73(1), 53-76. doi:10.1007/s11238-011-9270-7

Butler, D. J., Burbank,V. K., \& Chisholm, J. S. (2011). The Frames Behind the Games: Player's Perceptions of Prisoners Dilemma, Chicken, Dictator, and Ultimatum Games. The Journal of Socio-Economics, 40(2), 103-114.

Collins, S. (2013). Collectives' Duties and Collectivisation Duties. Australasian Journal of Philosophy, 91(2), 231-248.

Dietz, T., Gardner, G. T., Gilligan, J., Stern, P. C., \& Vandenbergh, M. P. (2009). Household Actions Can Provide a Behavioral Wedge to Rapidly Reduce US Carbon Emissions. Proceedings of the National Academy of Sciences, 106(44), 18452-18456.

Giubilini, A., Birkl, P., Douglas, T., Savulescu, J., \& Maslen, H. (2017). Taxing Meat: Taking Responsibility for One's Contribution to Antibiotic Resistance. Journal of Agricultural and Environmental Ethics, 30(2), 179-198.

Gold, N., \& Sugden, R. (2007). Collective Intentions and Team Agency. Journal of Philosophy, 104(3), 109-137.

Hakli, R., Miller, K., \& Tuomela, R. (2010). Two Kinds of We-Reasoning. Economics and Philosophy, 26(3), 291-320.

Held, V. (1970). Can a Random Collection of Individuals be Morally Responsible? Journal of Philosophy, 67(14), 471-481.

Isaacs, T. L. (2011). Moral Responsibility in Collective Contexts. Oxford University Press.

Lawford-Smith, H. (2015). What 'We'? Journal of Social Ontology, 1(2), 225-249.

Le Morvan, P. (2011). On Ignorance: A Reply to Peels. Philosophia, 39(2), 335-344.

Ludwig, K. (2016). From Individual to Plural Agency: Collective Action I. Oxford: Oxford University Press.

May, L. (1992). Collective Inaction and Responsibility. Sharing Responsibility (pp. 105-124): Chicago University Press.

Miller, S. (2010). The Moral Foundations of Social Institutions. A Philosophical Study. New York: Cambridge University Press.

Parfit, D. (1984). Five Mistakes in Moral Mathematics. Reasons and Persons (Vol. 1, pp. 55-83). Oxford: Clarendon Press.

Peels, R. (2010). What is Ignorance? Philosophia, 38(1), 57-67.

Peels, R. (2016). Perspectives on Ignorance From Moral and Social Philosophy. Routledge.

Pinkert, F. (2014). What We Together Can (Be Required to) Do. Midwest Studies in Philosophy, 38(1), 187-202.

Regan, D. (1980). Utilitarianism and Co-Operation (Vol. 33). Oxford University Press.

Rosen, G. (2003). IV-Culpability and Ignorance. Proceedings of the Aristotelian Society (Hardback), $103(1), 61-84$

Roy, O., \& Schwenkenbecher, A. (under review). Joint Agency, Loose Groups, and Pooled Knowledge.

Schlothfeldt, S. (2009). Individuelle oder gemeinsame Verpflichtung?: das Problem der Zuständigkeit bei der Behebung gravierender Übel. Paderborn: Mentis.

Schwenkenbecher, A. (2013). Joint Duties and Global Moral Obligations. Ratio, 26(3), 310-328.

Schwenkenbecher, A. (2014). Joint Moral Duties. Midwest Studies in Philosophy, 38(1), 58-74.

Schwenkenbecher, A. (2017). Gemeinsame Hilfspflichten, Weltarmut und kumulative Handlungen. Zeitschrift für Praktische Philosophie, 4(1), 123-150.

Schwenkenbecher, A. (2018). Making Sense of Collective Moral Obligations: A Comparison of Current Approaches. In T. Isaacs, K. Hess, \& V. Igneski (Eds.), Collectivity: Ontology, Ethics and Social Justice (pp. 109-132). Rowman and Littlefield.

Schwenkenbecher, A. (2019). Collective Moral Obligations: 'We-reasoning' and the Perspective of the Deliberating Agent. The Monist, 102(2), xx.

Shapiro, S. (2014). Massively Shared Agency. In M.Vargas \& G.Yaffe (Eds.), Rational and Social Agency. Essays on the Philosophy of Michael Bratman (pp. 257-293). Oxford: Oxford University Press.

Stemplowska, Z. (2016). Feasibility: Individual and Collective. Social Philosophy and Policy, 33(1-2), 273-291.

Sugden, R. (2015). Team Reasoning and Intentional Cooperation for Mutual Benefit. Journal of Social Ontology, 1(1), 143-166.

Sugden, R., \& Gold, N. (2007). Theories of Team Agency. In F. Peter \& H. B. Schmid (Eds.), Rationality and Commitment. Oxford: Oxford University Press. 
Tollefsen, D. (2015). Groups as Agents. Cambridge, UK: Polity Press.

Tomasello, M. (2014). A Natural History of Human Thinking. Cambridge, MA;London, England: Harvard University Press.

Tuomela, R. (2013). Social Ontology: Collective Intentionality and Group Agents. New York: Oxford University Press.

UNEP. (2017). The Emissions Gap Report 2017. A UN Environment Synthesis Report. Retrieved from https:// wedocs.unep.org/bitstream/handle/20.500.11822/22070/EGR_2017.pdf?isAllo...

Woodard, C. (2003). Group-based Reasons for Action. Ethical Theory and Moral Practice, 6(2), 215-229.

Woodard, C. (2017). Three Conceptions of Group-Based Reasons. Journal of Social Ontology (Vol. 3, pp. 107).

Wringe, B. (2005). Needs, Rights, and Collective Obligations. Royal Institute of Philosophy Supplement, 80(57), 187-207.

Wringe, B. (2010). Global Obligations and the Agency Objection. Ratio, 23(2), 217-231.

Wringe, B. (2016). Collective Obligations: Their Existence, Their Explanatory Power, and Their Supervenience on the Obligations of Individuals. European Journal of Philosophy, 24(2), 472-497.

Wynes, S., \& Nicholas, K. A. (2017). The Climate Mitigation Gap: Education and Government Recommendations Miss the Most Effective Individual Actions. Environmental Research Letters, 12(7), 074024 .

Zimmerman, M. J. (1996). The Concept of Moral Obligation. Cambridge: Cambridge University Press.

Zimmerman, M. J. (2014). Ignorance and Moral Obligation. Oxford: Oxford University Press.

Zimmerman, M. J. (2016). Ignorance as a Moral Excuse. In R. Peels (Ed.), Perspectives on Ignorance From Moral and Social Philosophy (pp. 77-94): Routledge. 